\title{
旋耕深度对西北黄土高原旱作区土壤水分特性和马铃薯产量的影响
}

\author{
张绪成 马一凡于显枫侯慧芝王红丽方彦杰张国平 \\ 雷康宁
}

甘肃省农业科学院旱地农业研究所 / 甘肃省旱作区水资源高效利用重点实验室, 甘肃兰州 730070

摘 要: 深耕对打破犁底层、优化土壤水分特性有积极作用, 但对旱作农田旋耕深度的土壤水分效应及其对马铃薯 水分耗散过程和产量的影响缺乏研究分析。本研究设 15 (TT)、40 (VRT)、60 cm (VRT6) 3 个旋耕深度, 测定土壤容 重和水分特性、马铃薯叶片 SPAD 值、叶面积指数(LAI)和产量等, 研究旋耕深度对马铃薯水分利用和产量的影响。 结果表明, 与 VRT 和 TT 相比, VRT6 分别在 $40 \sim 60 \mathrm{~cm}$ 和 $0 \sim 60 \mathrm{~cm}$ 土层降低土壤容重, 提高饱和含水量、毛管含水量 和田间持水量; VRT6 显著提高了马铃薯现蕾前的耗水量, 导致盛花期的土壤咜水量在 2016 年较 VRT 和 TT 下降了 $22.3 \mathrm{~mm} 、 49.0 \mathrm{~mm}, 2017$ 年下降了 $43.9 \mathrm{~mm}$ 、 $56.6 \mathrm{~mm}$; VRT6 显著提高 2017 年花后耗水, 分别较 VRT 和 TT 增加了 $42.2 \mathrm{~mm}$ 和 $38.3 \mathrm{~mm}$ 。旺盛的花前耗水促进了地上部发育, VRT6 的 LAI 在全生育期高于 TT, 在现蕾期至收获期高于 VRT, 并使 SPAD 值在 2017 年的块茎膨大期显著高于 VRT 和 TT, 呈现明显的地上部旺长特征。基于以上原因, VRT6 的块茎产量虽然高于 TT, 但在 2017 年显著低于 VRT, 而且水分利用效率(WUE)较 VRT 和 TT 下降了 $61.2 \%$ 67.5\% 和 $41.0 \%$ 53.5\%。因此, 在半干旱旱作区马铃薯种植的立式深旋耕作的适宜深度是 $40 \mathrm{~cm}$, 可在优化土壤水分特性和 耗水过程的基础上, 有效抵御季节性干旱胁迫, 显著提高产量和水分利用效率。

关键词：旋耕深度；土壤水分特性；阶段耗水量；产量；水分利用效率；马铃薯

\section{Effects of tillage depth on soil hydrological characteristics and potato yield on northwest Loess Plateau}

ZHANG Xu-Cheng ${ }^{*}$, MA Yi-Fan, YU Xian-Feng, HOU Hui-Zhi, WANG Hong-Li, FANG Yan-Jie, ZHANG Guo-Ping, and LEI Kang-Ning

Institute of Dry Land Farming, Gansu Academy of Agricultural Sciences / Key Laboratory of High Water Utilization on Dryland of Gansu Province, Lanzhou 730070, Gansu, China

\begin{abstract}
The subsoiling can break the plough pan and optimize soil hydrological characteristics. However, the study on the effects of tillage depths on soil water characteristics, potato water consumption and yield, is insufficient. The field experiment was conducted with three tillage depths of $15 \mathrm{~cm}$ (TT), $40 \mathrm{~cm}$ (VRT), and $60 \mathrm{~cm}$ (VRT6), to investigate the effect of tillage depths on the yield and water utilization of potato in semiarid rain-fed area in 2016 and 2017 on northwest Loess Plateau. The parameters of soil bulk density, soil hydrological properties, potato SPAD (soil and plant analyzer development) value, leaf area index (LAI), and tuber yield were measured. The soil bulk density, and increased saturation moisture, capillary moisture and field water capacity of VRT6 treatment compared with VRT and TT were decreased in 40-60 cm and 0-60 cm profile, respectively. Water consumption of VRT6 treatment was significantly increased in pre-squaring stage, resulting in the decrement of soil water storage in $0-100 \mathrm{~cm}$ profile by $22.3 \mathrm{~mm}$ and $49.0 \mathrm{~mm}$ in 2016 , and $43.9 \mathrm{~mm}$ and $56.6 \mathrm{~mm}$ in 2017 . Water consumption in pre-squaring stage of VRT6 was significantly increased by $42.2 \mathrm{~mm}$ and $38.3 \mathrm{~mm}$ compared with VRT and TT treatment in 2017, respectively. Based on the excessive water consumption in pre-flowering period, the LAI of VRT6 was significantly higher than TT in whole growth period, than VRT in post-squaring period, and the SPAD value was higher than VRT in expanding stage in 2017, which indicated that the vigorous growth was subsistent in VRT6 treatment. The tuber yield of VRT6 were significantly higher than TT, but it
\end{abstract}

本研究由国家重点研发计划项目(2018YFD020080105)和国家自然科学基金项目(31960398, 31560355)资助。

This study was supported by the National Key Research and Development Program of China (2018YFD020080105) and the National Natural

Science Foundation of China (31960398, 31560355).

*通信作者(Corresponding author): 张绪成, E-mail: gazhangxuch@163.com

Received (收稿日期): 2020-03-12; Accepted (接受日期): 2020-07-02; Published online (网络出版日期): 2020-08-18.

URL: https://kns.cnki.net/kcms/detail/11.1809.S.20200818.1619.008.html 
significantly decreased in 2017 compared to VRT, and the water use efficiency (WUE) of VRT6 were significantly decreased by $61.2 \%-67.5 \%$ and $41.0 \%-53.5 \%$, as compared with VRT and TT. Consequently, the suitable tillage depth for potato cultivation was $40 \mathrm{~cm}$ in semiarid area, which could optimize the soil hydrological properties and potato water consuming process, and relieved the drought stress efficiently, resulting in significantly higher tuber yield and WUE.

Keywords: tillage depths; soil hydrological properties; periodical water consumption; tuber yield; water use efficiency, potato.

西北黄土高原降水少、蒸发强，但深厚的土层 是有效的“土壤水库” ${ }^{[1]}$, 在缓解干旱胁迫中发挥了 至关重要的作用。机械化旋耕技术的应用大幅度提 高了耕作效率，但长期旋耕形成了相对坚硬的犁底 层, 耕层呈逐年变浅的态势, 使得土壤物理性状恶 化，并由此导致耕地质量和生产力下降 ${ }^{[2-5]}$ 。谢军红 等 ${ }^{[6]}$ 报道, 旋耕 $0 \sim 30 \mathrm{~cm}$ 土层的土壤容重随土层深 度增加呈增大趋势, 形成了较为坚硬的犁底层, 使 作物产量下降 ${ }^{[7]}$; 石否等 ${ }^{[8]}$ 在陕北黄土高原调查结 果显示, 土壤犁底层变浅、容重和紧实度增加, 影响 作物根系下扎和水分养分运移, 是长期旋耕造成土 壤障碍的主要因素, 导致生产力明显下降。针对这一 问题，农业农村部出台了《全国农机深松整地作业实 施规划(2016-2020 年)》, 以通过深松打破犁底层, 优化土壤水肥环境和提高作物资源利用效率 ${ }^{[9-12]}$ 。

马铃薯是西北黄土高原半干旱区主栽作物之一, 该区也是我国马铃薯优势产区和主产区 ${ }^{[13]}$ 。以甘肃 省为例, 2017 年全省马铃薯播种面积超过 66.7 万公 顷, 总产量达到 1200 万吨 ${ }^{[14]}$, 虽然在全膜覆盖条件 下显著提高了降水利用率, 但单产低于全国平均水 平 ${ }^{[15]}$, 这主要是季节性干旱胁迫、耕地质量较差等 因素共同作用的结果。因此，通过优化耕作措施来 增强土壤的水肥供应能力 ${ }^{[16-17]}$, 将是进一步提高旱 作马铃薯产量的主要方向之一。立式深旋耕作 (粉垄 技术、深旋松技术)是首先应用于山药的一项耕作技 术, 其特点是利用螺旋犁头, 将土壤粉碎但不改变 土壤的垂直层次结构, 结合了深松和旋耕的优点, 旋耕深度可达到 $60 \mathrm{~cm}$ 以上 ${ }^{[18-20]}$ 。Zhai 等 ${ }^{[21]}$ 在黄淮 海玉米上的研究表明, 深旋松(立式深旋耕作)能够 显著降低土壤容重, 提高土壤通透性, 提高土壤蓄 水能力, 促进玉米根系发育, 使产量和水分利用效 率显著增加; 在东北棕壤上也取得了相似的研究结 果。目前，该项技术在玉米、小麦、山药、花生、 大豆、水稻、甘蔗、马铃薯等作物上取得了显著增 产效果 ${ }^{[18-23]}$ 。我们在半干旱区马铃薯上的研究也证 明, 立式深旋技术能够显著降低黄绵土的土壤容重, 提高土壤孔隙度, 改善土壤水分特性, 实现马铃薯 的抗旱增产 ${ }^{[23-24]}$ 。
旋耕深度是影响土壤特性尤其是水分性状的一 个关键因素, 增加耕作深度能够改善土壤水分状况 和促进作物生长发育, 这已在松辽平原玉米 ${ }^{[25]}$ 、黄 淮海平原冬小麦 ${ }^{[26]}$ 、胶东平原 ${ }^{[27]}$ 和黄土高原半干旱 区马铃薯 ${ }^{[24]}$ 上得到证明, 认为增加耕作深度提高了 土壤咜水量和作物地上、下部生长发育。然而, 耕 作深度对作物生长发育的影响因作物而异, 当旋耕 深度增加到 $40 \mathrm{~cm}$ 时, 产量反而下降 ${ }^{[26]}$ 。但对于块 茎类作物如马铃薯, 增加旋耕深度一方面能够优化 土壤的水分特性, 提高土壤水肥供应能力而增强抗 旱性; 另外, 疏松的土壤有利于块茎生长, 这同样 是提高产量的一个积极因素。进一步加深旋耕深度 将会促进水肥在土壤中的运移, 是否具有进一步提 升产量和作物抗旱性的作用, 并通过影响作物的耗 水进程以缓解季节性干旱对作物生产的胁迫强度? 目前对此尚无探讨。将立式深旋耕作的旋耕深度增 加至 $60 \mathrm{~cm}$, 研究不同旋耕深度对土壤水分性状和 马铃薯生长发育的影响, 将为建立马铃薯水分高 效、产量提升的耕作制度提供依据。鉴于此, 本研 究设置了 15、40 和 $60 \mathrm{~cm} 3$ 种旋耕深度, 研究其对 马铃薯阶段耗水、干物质积累、叶面积指数、叶片 SPAD 值, 以及产量、水分利用效率的影响, 以期为 确定西北黄土高原旱作区马铃薯抗旱增产的耕作技 术提供理论依据。

\section{1 材料与方法}

\section{1 试验地概况}

试验于 2016-2017 年在甘肃省农业科学院定西 试验站 (甘肃省定西市安定区团结镇唐家堡村, $\left.104^{\circ} 36^{\prime} \mathrm{E}, 35^{\circ} 35^{\prime} \mathrm{N}\right)$ 进行。该区属于典型的半干旱雨 养农业区, 也是我国优质马铃薯主产区之一。区域 多年平均降水为 $415 \mathrm{~mm}$, 年平均蒸发量高达 $1500 \mathrm{~mm}$, 春季低温少雨, 降水主要集中在秋季, 7 月至 9 月份降水平均占全年总量的 $65 \%$ 。试区属中 温带半干旱气候, 海拔高度为 $1970 \mathrm{~m}$, 作物一年一 熟; 多年平均气温 $6.2^{\circ} \mathrm{C}, \geq 10^{\circ} \mathrm{C}$ 积温 $2075.1^{\circ} \mathrm{C}$, 无霜 期 $140 \mathrm{~d}$, 为典型的寒旱农业区; 光照充足, 多年平 均日照时数为 $2500 \mathrm{~h}$, 年总辐射量达 $5898 \mathrm{MJ} \mathrm{m}^{-2}$ 。 
试验区土壤属于黄绵土, 土层厚度达 $50 \mathrm{~m}$ 以上。土 质相对疏松, 0 30 cm 土层平均容重 $1.25 \mathrm{~g} \mathrm{~cm}^{-3}$, 田 间持水量和调萎系数分别为 $21.18 \%$ 和 $7.2 \%$, 土壤质 量较差, 有机质含量在 $10 \mathrm{~g} \mathrm{~kg}^{-1}$ 左右。

2016 年马铃薯生育期内降水量为 $179.3 \mathrm{~mm}$, 全 年降水量为 $289.3 \mathrm{~mm}$, 分别占多年平均的 $68.7 \%$ 和 $55.2 \%$, 属严重干旱年份; 2016 年平均气温为 $7.5^{\circ} \mathrm{C}$,
较多年平均增加了 $1.3^{\circ} \mathrm{C}$, 因此, 该年为干旱和高温 年份, 对马铃薯生产有不利影响。2017 年马铃薯生 育期内降水量为 $353.5 \mathrm{~mm}$, 全年降水量为 $430.3 \mathrm{~mm}$, 属于平水年, 但 2 年均在马铃薯盛花期发生持续干 旱，季节分配不均(图 1)；2017 年气温与多年平均温 度基本持平。2 年的降水和气温有明显不同, 对马铃 薯的生长造成了较明显的影响。

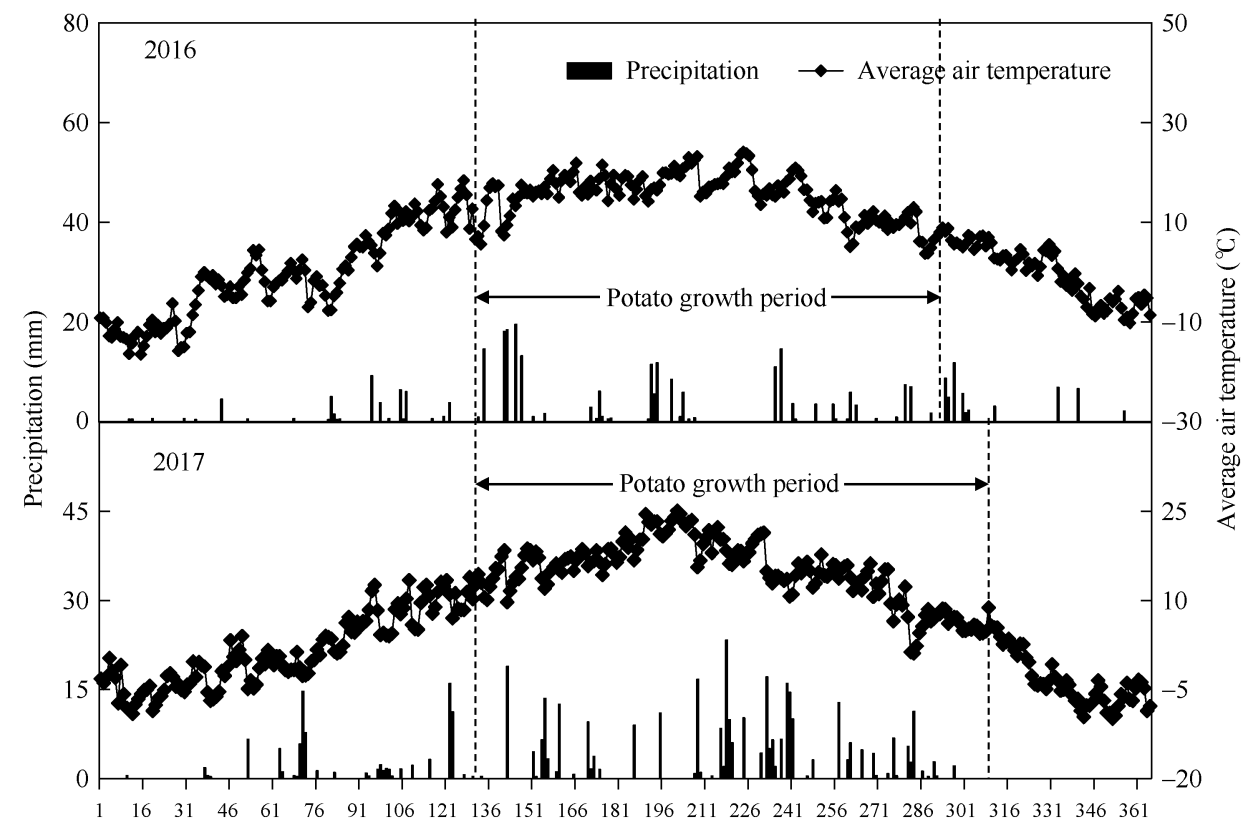

Day (s) (d)

图 $12016-2017$ 试验区降水分布和平均气温变化

Fig. 1 Variation of precipitation and average air temperature in experimental plots from 2016 to 2017

\section{2 试验设计}

试验采用随机区组设计, 设置 3 个旋耕深度, 即传统旋耕 $15 \mathrm{~cm}$ (traditional rotary tillage, TT)、立 式深旋松耕 $40 \mathrm{~cm}$ (vertically rotary sub-soiling tillage, VRT)和立式深旋松耕 $60 \mathrm{~cm}$ (VRT6) 3 个处理, 均在 2016 和 2017 年的 3 月中旬机械耕作。耕作后即施肥、 起垄和覆盖地膜。每处理 3 次重复, 小区面积 $6 \mathrm{~m} \times$
$10 \mathrm{~m}=60 \mathrm{~m}^{2}$ 。采用全膜覆盖垄上微沟种植方法(图 2), 大垄宽为 $60 \mathrm{~cm}$, 大沟宽为 $40 \mathrm{~cm}$, 在大垄上开微沟, 微沟宽度为 $20 \mathrm{~cm}$, 微沟内每 $50 \mathrm{~cm}$ 打孔以确保降水 入渗。马铃薯在垄顶部按“品”字形种植, 种植密度 60,000 穴 $\mathrm{hm}^{-2}$, 每穴种植 1 株。2016 年和 2017 年 均在 4 月 20 日播种, 2016 年 9 月上旬收获, 2017 年 10 月上旬收获。土壤水分均在微沟内取样。

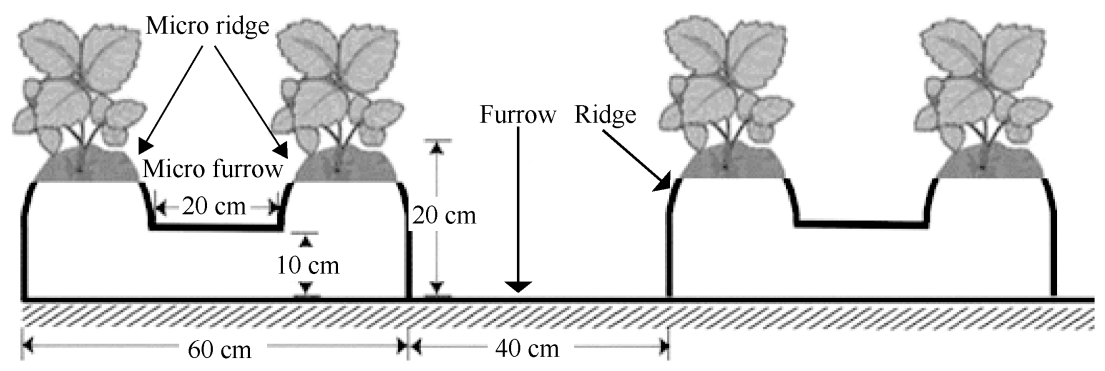

图 2 马铃薯全膜覆盖垄上微沟种植技术示意图

Fig. 2 Schematic diagram of potato micro-furrows on ridges and planting with plastic mulching 


\section{3 测定指标及方法}

\subsection{1 土壤物理性状参照土壤理化分析的方} 法 ${ }^{[25]}$ 测定马铃薯播前 $0 \sim 10 、 10 \sim 20 、 20 \sim 40 、 40 \sim 60$ 、 60 80、80 100 cm土层的土壤容重、田间持水量、 饱和含水量、毛管含水量。采用环刀法(环刀容积为 $100 \mathrm{~cm}^{3}$ )测定土壤容重。利用测定容重的环刀浸入水 中 $24 \mathrm{~h}$, 称重至恒质量, 按公式(1)计算田间持水量, 公式(2)计算饱和含水量; 将饱和后的环刀样置于铝 盒上, 中间用滤纸隔开, 放置 $12 \mathrm{~h}$ 烘干至恒质量, 并 称重, 按照公式(3)计算土壤毛管含水量。

饱和含水量 $(\%)=$ (浸泡后土质量-烘干土质量 $)$ /烘干土质量 $\times 100 \%$

土壤毛管含水量 $(\%)=($ 放置后的土质量-烘干 的土质量) /烘干的土质量 $\times 100 \%$

田间持水量 $(\%)=($ 浸泡后土质量-烘干土质量 $)$ $/ 100$

1.3.2 土壤拒水量 于马铃薯播前、现蕾期、盛 花期和收获期用烘干法测定 0 200 $\mathrm{cm}$ 土层土壤含水 量, 每 $20 \mathrm{~cm}$ 为 1 个层次, 每小区在垄上微沟内的马铃 薯株间测定1个位点。按照公式(4)计算土壤䛎水量。

$\operatorname{SWS}(\mathrm{mm})=\mathrm{SWC} \times \gamma \times \mathrm{d} / 100$

式中, $S W C$ 为土壤重量含水量 $\left(\mathrm{g} \mathrm{kg}^{-1}\right) ; \gamma$ 为土壤容重 $\left(\mathrm{g} \mathrm{cm}^{-3}\right) ; \mathrm{d}$ 为土壤深度 $(\mathrm{cm})$ 。

1.3.3 SPAD和LAI 于马铃薯现蕾期、盛花期和 块茎膨大期, 在晴天10:00用SPAD-502 PLUS (柯尼卡 美能达, 日本)测定叶片SPAD值, 选择倒二枝的顶叶 为测定对象, 每个叶片避开叶脉自上而下测定3次, 每小区选择10个叶片。同时用美国CID公司生产的 CI-110植物冠层数字图像分析仪测定叶面积指数
(LAI), 每小区测定3次, 计算其平均数为小区LAI。 1.3.4 水分利用效率的计算 测定马铃薯播前和 收获后0 200 $\mathrm{cm}$ 土层的土壤含水量, 按照公式(5)计 算马铃薯水分利用效率。

WUE $\left(\mathrm{kg} \mathrm{hm}^{-2} \mathrm{~mm}^{-1}\right)=$ 块茎产量 $\left(\mathrm{kg} \mathrm{hm}^{-2}\right) / \mathrm{ET}$ $(\mathrm{mm})$

式中, 块茎产量由小区实际测定产量换算得出, ET 为蒸散量, 按照公式(6)计算。

$\mathrm{ET}=$ 播前土壤咜水量 $(\mathrm{mm})-$ 收获后土壤䛎水 量 $(\mathrm{mm})+$ 降水量 $(\mathrm{mm})$

\section{4 数据处理}

用Microsoft Excel 2003和DPS v3.01专业版统 计分析软件处理数据, Tukey法检验处理间的差异 显著性。

\section{2 结果与分析}

\section{1 不同旋耕深度对土壤容重的影响}

立式深旋耕作能显著降低土壤容重(图 3)。与 TT 相比, VRT 在 0 10、10 20 和 20 40 cm 土层的土 壤容重在 2016 年分别降低了 $11.8 \%$ 、12.1\%和 $20.2 \%$, 2017 年分别降低了 $13.3 \%$ 、13.8\%和 $25.3 \%$, 均达到 显著差异水平, 在 $40 \sim 100 \mathrm{~cm}$ 土层无显著差异。 VRT6 在 $0 \sim 10 、 10 \sim 20 、 20 \sim 40$ 和 40 60 $\mathrm{cm}$ 土层的 土壤容重 2016 年分别降低了 $13.2 \% 、 13.7 \% 、 25.7 \%$ 和 $10.5 \%, 2017$ 年相应地降低了 $12.1 \% 、 10.1 \%$ 、 $32.9 \%$ 、 $23.8 \%$ ，但在 $60 \sim 100 \mathrm{~cm}$ 土层二者无显著差 异。与 VRT 相比, VRT6 在 40 60 cm 土层的土壤容 重分别在 2016 年和 2017 年下降 $20.0 \%$ 和 $18.1 \%$, 达 到显著差异，在其余土层二者无显著差异。

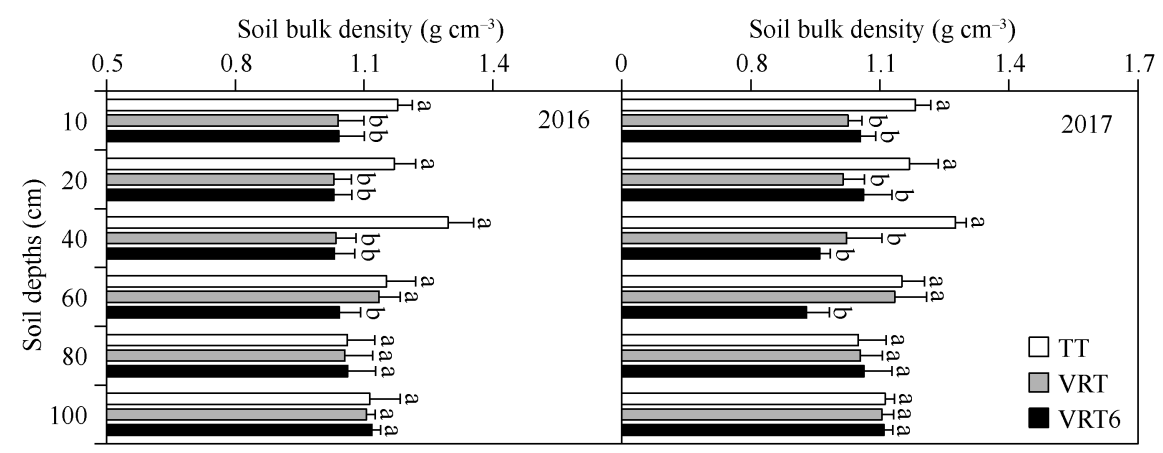

图 3 不同旋耕深度对土壤容重的影响

Fig. 3 Effects of different tillage depths on soil bulk density

TT: 传统旋耕 $15 \mathrm{~cm}$; VRT: 立式深旋松耕 $40 \mathrm{~cm}$; VRT6: 立式深旋松耕 $60 \mathrm{~cm}$ 。在同一土层标记不同小写字母表示处理间在 0.05 水平 差异显著。

TT: traditional votary tillage at $15 \mathrm{~cm}$ soil depth; VRT: vertically rotary tillage at $40 \mathrm{~cm}$ depth; VRT6: vertically rotary tillage at $60 \mathrm{~cm}$ depth. The bars with different lowercase letters in the same soil depth mean significant difference among treatments at the 0.05 probability level. 


\section{2 不同旋耕深度对土壤水分特性的影响}

与 TT 相比, VRT 在 $0 \sim 10 、 10 \sim 20 、 20 \sim 40 \mathrm{~cm}$ 土 层的饱和含水量在 2016 年增加了 $27.0 \%$ 、34.1\%和 $53.4 \%, 2017$ 年则相应地提高了 $27.3 \%$ 、35.1\%和 $48.0 \%$ ，达到显著差异水平，其余土层差异不显著; VRT6 在 0 10、10 20、20 40 和 40 60 $\mathrm{cm}$ 土层的 土壤饱和含水量在 2016 年分别增加了 $30.8 \%$ 、 $34.8 \%$ 、 $43.7 \%$ 和 $25.5 \%, 2017$ 年这一数值为 $30.7 \%$ 、 $33.6 \% 、 53.9 \%$ 和 31.3\% (图 4-a, d), 均达到显著差异, 在 60 100 cm 土层无显著差异; VRT6 在 $40 \sim 60 \mathrm{~cm}$ 的 饱和含水量较 VRT 在 2016 和 2017 年分别显著提高 了 $24.8 \%$ 和 $30.4 \%$, 但在其余土层无显著差异。与饱 和含水量结果相似, VRT6 在 $0 \sim 60 \mathrm{~cm}$ 土层、VRT 在 0 40 cm 土层, 均较 TT 显著提高了土壤毛管含水量, VRT6 的增加幅度在 2016 年和 2017 年的分别为
$30.5 \% \sim 57.2 \%$ 和 $32.6 \% \sim 57.4 \%$, VRT 则分别为 $27.0 \% \sim 53.4 \%$ 和 $32.8 \% \sim 57.9 \%$ (图 4-b, e)。与 TT 相 比，VRT6 显著提高了 $0 \sim 60 \mathrm{~cm}$ 土层田间持水量， 2016 年和 2017 分别增加了 $7.8 \%$ 24.1\%和 $8.8 \%$ $29.8 \%$, VRT 在 $0 \sim 40 \mathrm{~cm}$ 土层的田间持水量则分别提 高了 9.3\% 22.3\%和 9.4\% 24.7\% (图 4-c，f)。VRT6 和 VRT 的土壤饱和含水量、毛管含水量和田间持水 量在 20 40 cm 土层的增加幅度最大，表明多年浅旋 耕在这一层次形成了较为坚硬的犁底层。

\section{3 不同旋耕深度对土壤咜水量的影响}

2016 年播前, VRT6 在 $0 \sim 60 \mathrm{~cm} 、$ VRT 在 $0 \sim 40 \mathrm{~cm}$ 土层的土壤咜水量较 $\mathrm{TT}$ 分别增加了 $12.0 \mathrm{~mm}$ 和 $12.7 \mathrm{~mm}$, VRT6 在 $40 \sim 60 \mathrm{~cm}$ 土层的土壤䛎水量较 VRT 增加了 $2.8 \mathrm{~mm}$, 均达到显著差异(图 5-a), 现蕾 期 VRT6 和 VRT 的土壤咜水量在 0 20 cm 土层无显

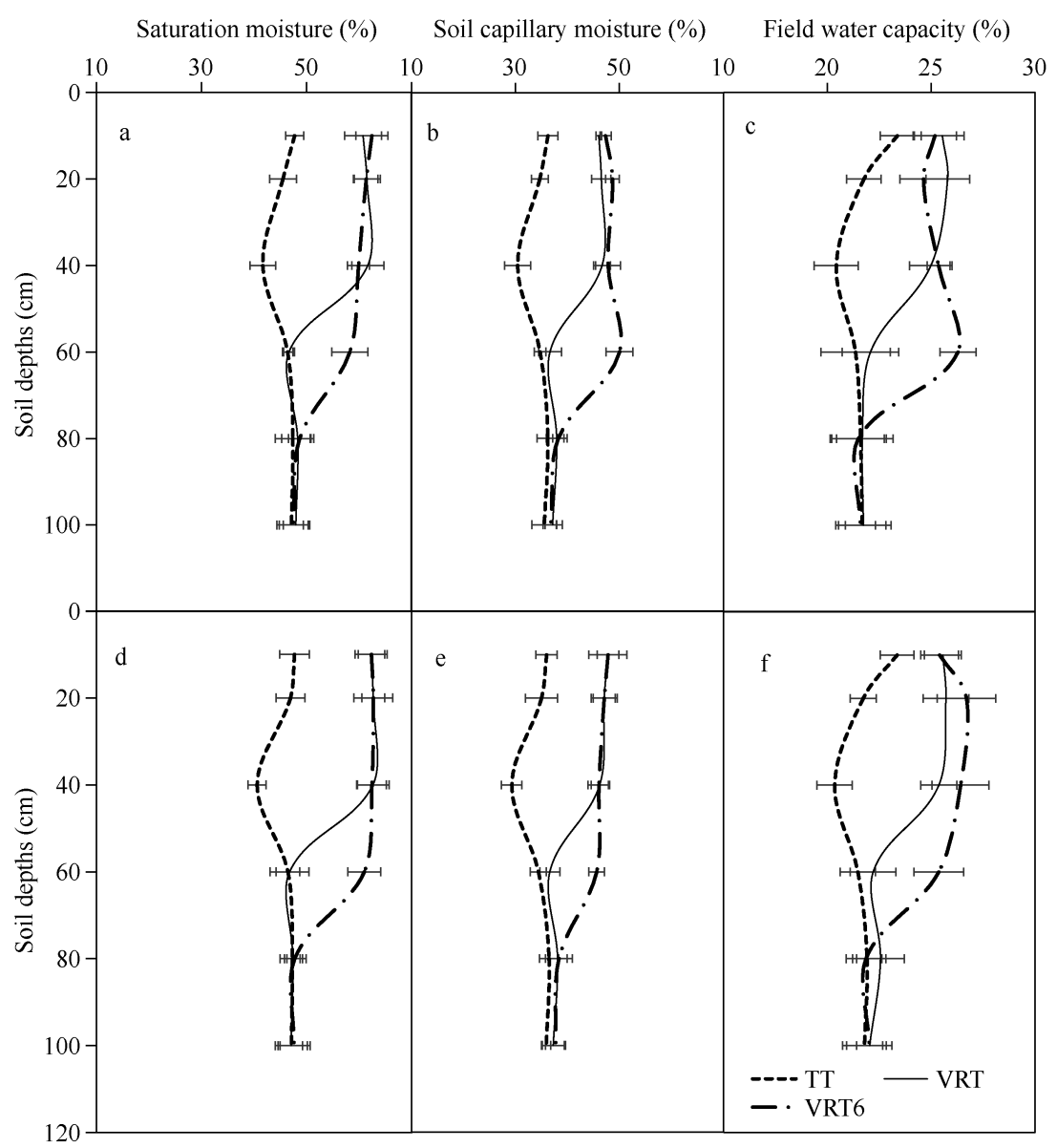

图 4 不同旋耕深度对土壤饱和含水量、毛管含水量和田间持水量的影响

Fig. 4 Effects of different tillage depths on soil saturation moisture, capillary moisture, and field water capacity

图 $\mathrm{a} 、 \mathrm{~b} 、 \mathrm{c}$ 和 $\mathrm{e} 、 \mathrm{~d}$ 、 f 分别为 2016 年和 2017 年的土壤饱和含水量、毛管含水量和田间持水量。在同一土层标记不同小写字母表示处 理间在 0.05 水平差异显著。处理同图 3。

$\mathrm{a}, \mathrm{b}, \mathrm{c}$ and e, d, f indicate the soil saturation moisture, capillary moisture and field water capacity in 2016 and 2017, respectively. Bars with different lowercase letters in the same soil depth mean significant difference among treatments at the 0.05 probability level. Treatments are the same as those given in Fig. 3. 
著差异, 但显著高于 TT, 且 VRT6 在 160 200 cm 土 层显著低于 VRT 和 TT (图 5-b); 在盛花期的 20 100 cm 土层, VRT6 较 VRT 下降了 $18.2 \mathrm{~mm}$; 在 20 140 cm 土层, VRT6 和 VRT 较 TT 分别下降了 $61.0 \mathrm{~mm}$ 和 $39.7 \mathrm{~mm}$, 均达到显著差异(图 5-c)。在收 获期的 80 200 cm 土层, VRT6 的土壤咜水量较 VRT 和 $\mathrm{TT}$ 分别降低了 $47.0 \mathrm{~mm}$ 和 $98.3 \mathrm{~mm}$; 在 100 200 cm 土层, VRT 较 TT 下降了 $51.7 \mathrm{~mm}$, 均达 到显著差异(图 5-d)。2017 年播前, VRT6 在 0 100 cm 土层土壤咜水量较 VRT 和 TT 分别下降了 $59.6 \mathrm{~mm}$ 和 $34.7 \mathrm{~mm}$, 而 VRT 较 TT 在 40 120 cm 土层增加了 $39.2 \mathrm{~mm}$, 但 TT 在 160 200 cm 土层较 VRT6 和 VRT 分别增加了 $20.0 \mathrm{~mm}$ 和 $12.3 \mathrm{~mm}$ (图 5-e), 均达到显 著差异。在现蕾期, VRT6 在 $0 \sim 120 \mathrm{~cm}$ 土层的土壤咜
水量较 TT下降了 $66.1 \mathrm{~mm}$, 并在各层次达到显著差 异; 在 $0 \sim 100 \mathrm{~cm}$ 土层较 VRT 下降了 $55.3 \mathrm{~mm}$, 各层 次差异显著; 在 $0 \sim 140 \mathrm{~cm}$ 土层, 3 个处理无显著差异 (图 5-f); 在盛花期, VRT6 分别在 0 60 cm 较 VRT、 0 80 cm 土层较 TT下降了 $43.9 \mathrm{~mm}$ 和 $65.3 \mathrm{~mm}$, 各 层次均达到显著差异水平; 但在 120 200 cm 土层, VRT6 较 VRT 显著增加了 $24.5 \mathrm{~mm}$, 较 TT 增加了 $15.6 \mathrm{~mm}$, 且在 140 160、180 200 cm 土层达到显 著差异(图 5-g)。在收获期, VRT6 在 $0 \sim 120 \mathrm{~cm}$ 较 VRT 和 TT 分别显著下降了 $103.4 \mathrm{~mm}$ 和 $115.6 \mathrm{~mm}$, 在各土层均达到显著差异, 但 VRT 和 TT 之间无差 异; 在 140 180 cm 土层, VRT6 显著高于 VRT, 但 和 TT 之间差异不明显; 其他层次 3 个处理无显著 差异(图 5-h)。

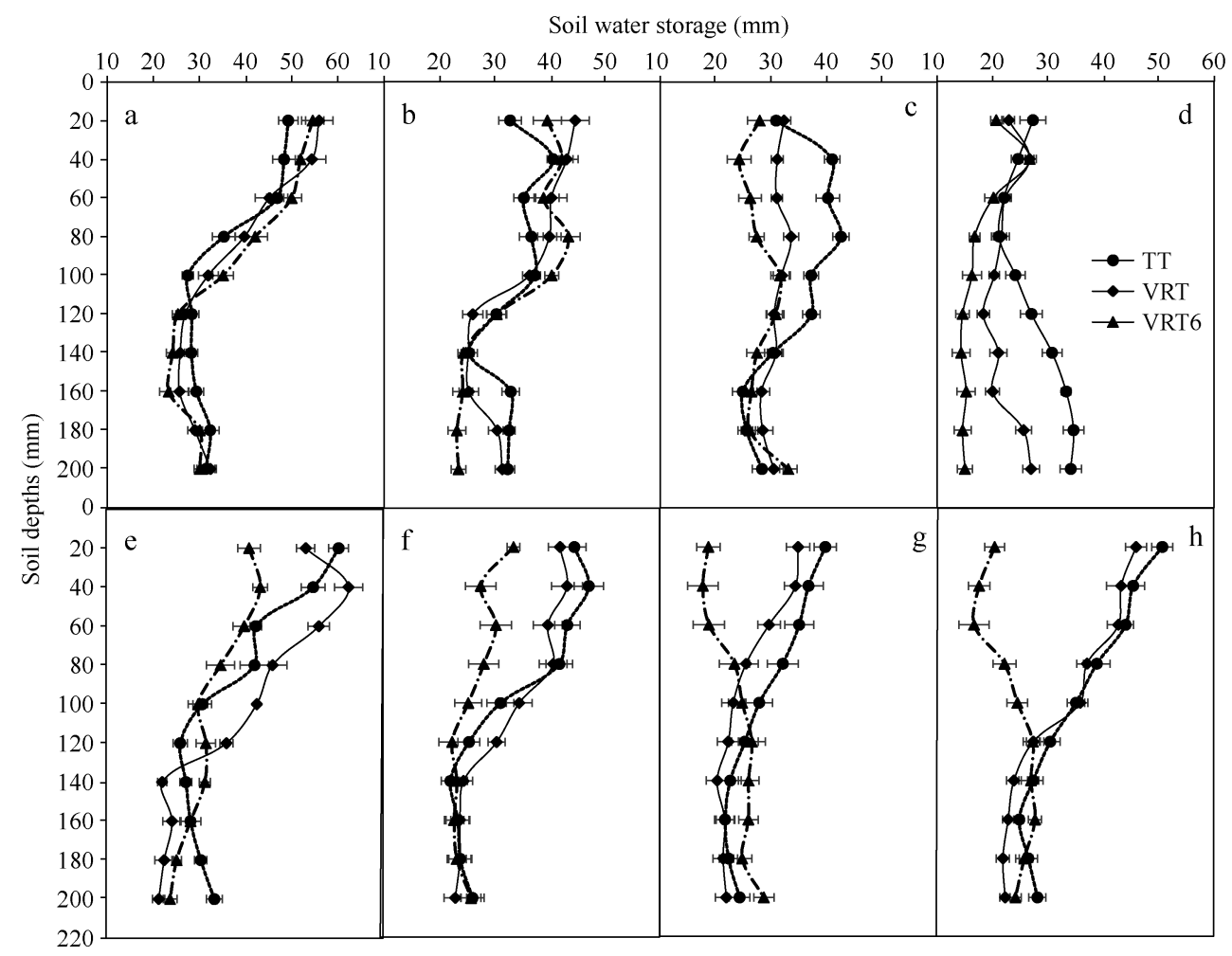

图 5 不同旋耕深度对土壤剖面接水量的影响

Fig. 5 Effects of different tillage depths on profile soil water storage

图 a, b, c, d 和 e, f, g, h 分别为 2016 年和 2017 年的播前、现蕾期、盛花期和收获期。处理同图 3 。

a, b, c, d and e, f, g, h indicate the pre-sowing stage, squaring stage, flowering stage and harvesting stage in 2016 and 2017 , respectively. Treatments are the same as those given in Fig. 3.

\section{4 不同旋耕深度对马铃薯阶段耗水量的影响}

VRT6 在播种到现蕾期的耗水量在 2016 年和 2017 年分别较 VRT 增加了 $41.9 \% 、 40.7 \%$, 较 TT 增 加了 $88.5 \%$ 、 $56.9 \%$; VRT 较 TT 在 2016 年增加了 $32.8 \%$, 差异显著(图 6)。在现蕾到盛花期, 2016 年 VRT6 较 VRT 和 TT 分别增加了 $81.1 \%$ 和 $144.2 \%$,
VRT 较 TT 增加了 $34.8 \% ; 2017$ 年 VRT6 的耗水量最 低, 分别较 VRT 和 TT 下降了 $53.5 \%$ 、26.6\%, TT 较 VRT 下降了 $57.8 \%$ 。在盛花期至收获期, 2016 年 3 个处理耗水量之间无显著差异, 但 2017 年 VRT6 较 VRT 和 TT 显著增加了 $42.2 \% 、 38.3 \%$, VRT 和 TT 之间无显著差异。 


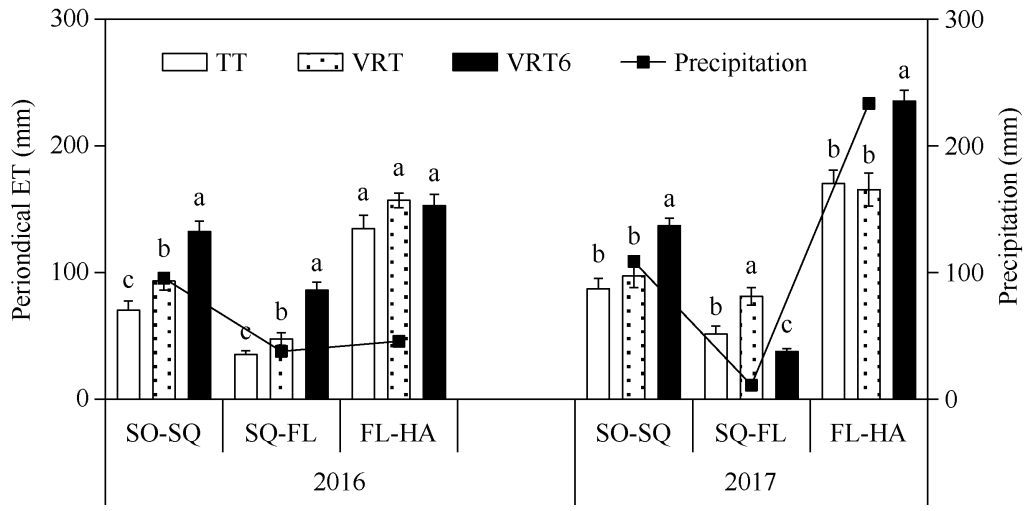

图 6 不同旋耕深度对马铃薯阶段耗水量的影响

Fig. 6 Effects of different tillage depths on periodical evapotranspiration of potato

图柱为阶段耗水量, 图线为阶段降水量。标以不同小写字母表示处理间在 0.05 水平差异显著。处理同图 3。

The bar represents the periodical evapotranspiration, the line represents the periodical precipitation. The bar with different lowercase letters mean significant difference among treatments at the 0.05 probability level. Treatments are the same as those given in Fig. 3 .

\section{5 不同旋耕深度对马铃薯 SPAD 值和叶面积指} 数的影响

3 种旋耕深度的马铃薯叶片 SPAD 值在苗期 和现蕾期无显著差异(图 7)。在盛花期, 2016 年 VRT6 较 TT 显著增加了 $32.7 \% ; 2017$ 年 3 个处理 间差异不显著。在块茎膨大期, VRT6 的 SPAD 值 在 2016 和 2017 年较 TT 分别增加了 $41.3 \%$ 、27.8\%, 并在 2017 年与 VRT 差异显著; VRT 的马铃薯叶片 SPAD 值在 2016 年和 2017 年较 TT 分别增加了
$25.2 \% 、 21.8 \%$ ，均达到显著差异。VRT6 的叶面积 指数(LAI)在 2 年的不同生育时期均高于 VRT 和 $\mathrm{TT}$ ，并在全生育期与 $\mathrm{TT}$ 达到显著差异, 2016 年和 2017 年分别增加了 $29.9 \%$ 64.3\%、34.1\% 114.8\%; 在现蕾期至块茎膨大期与 VRT 达到显著差异, 分 别增加了 $17.0 \%$ 38.4\%、17.1\% 56.6\%。在现蕾期 至块茎膨大期, VRT 的 LAI 显著高于 TT, 2016 年 和 2017 年分别增加了 $16.7 \%$ 27.0\%、14.5\% $37.1 \%$ 。

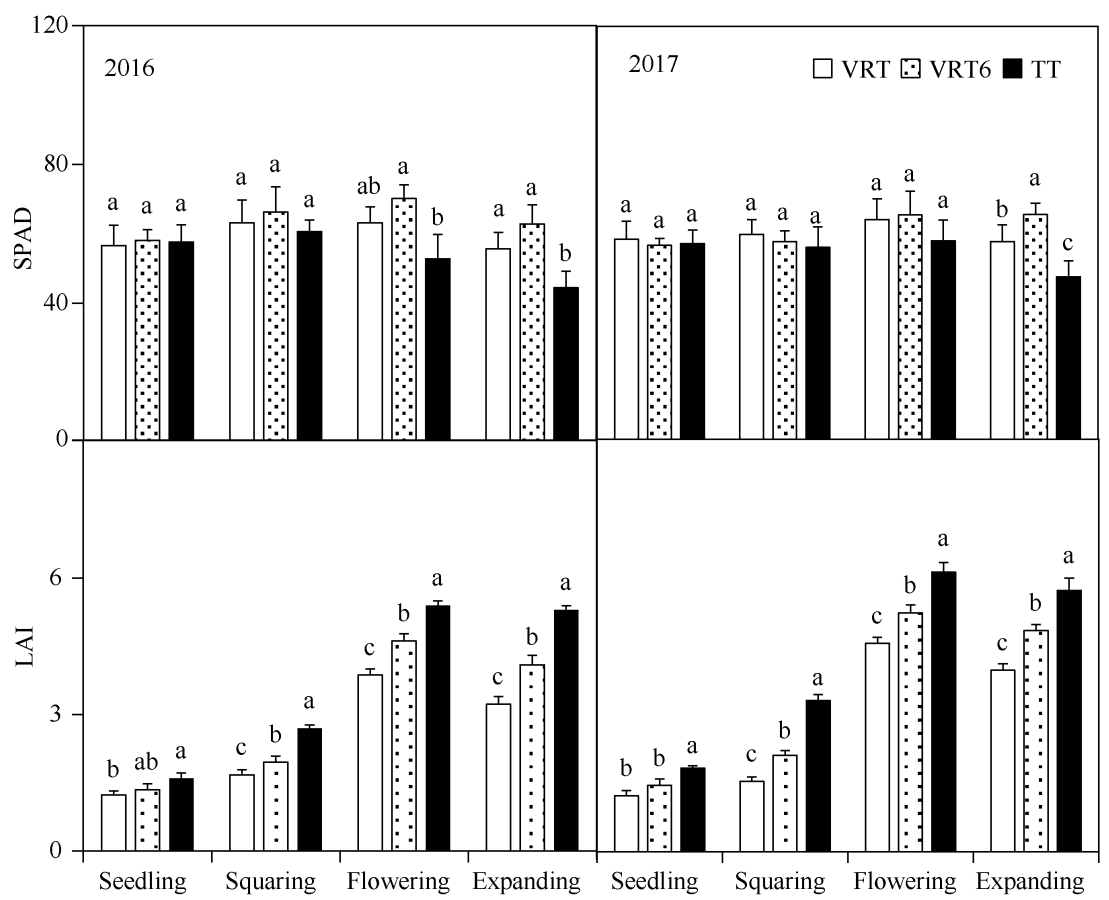

图 7 不同旋耕深度对马铃薯叶片 SPAD 值和叶面积指数的影响

Fig. 7 Effects of different tillage depths on leaf SPAD value and leaf area index of potato 标以不同小写字母表示处理间在 0.05 水平差异显著。处理同图 3 。

The bar with different lowercase letters mean significant difference among treatments at the 0.05 probability level. Treatments are the same as those given in Fig. 3. 
2.6 不同旋耕深度对马铃薯产量、耗水量和水分 利用效率的影响

VRT6 和 VRT 的块茎产量在 2016 年较 TT 分 别增加了 $49.9 \%$ 、 $47.8 \%, 2017$ 年增加 $19.3 \%$ 、 $41.0 \%$, 均达显著差异; 但在 2017 年, VRT6 的产 量较 VRT 显著下降了 $15.4 \%$, 并呈显著差异水平 (表 1)。VRT6 的耗水量在 2 年均显著高于 VRT
和 TT, 2016 年和 2017 年分别增加了 $24.7 \% 、 54.7 \%$ 和 $19.2 \% 、 32.7 \%$; 而且 VRT 耗水量在 2016 年和 2017 年较 TT 增加了 $24.0 \% 、 11.3 \%$ 。VRT6 的水 分利用效率(WUE)显著低于 VRT 和 TT, 2016 年和 2017 年分别下降了 $67.5 \% 、 61.2 \%$ 和 $53.5 \% 、 41.0 \%$; VRT 较 TT 在 2016 年和 2017 年分别增加了 $19.5 \% 、 26.7 \%$ 。

表 1 不同旋耕深度对马铃薯产量、耗水量和水分利用效率的影响

Table 1 Effects of different tillage depths on tuber yield, evapotranspiration, and water use efficiency of potato

\begin{tabular}{|c|c|c|c|c|}
\hline $\begin{array}{l}\text { 年份 } \\
\text { Year }\end{array}$ & $\begin{array}{c}\text { 处理 } \\
\text { Treatment }\end{array}$ & $\begin{array}{c}\text { 产量 } \\
\text { Yield }\left(\mathrm{kg} \mathrm{hm}^{-2}\right) \\
\end{array}$ & $\begin{array}{l}\text { 耗水量 } \\
\mathrm{ET}(\mathrm{mm})\end{array}$ & $\begin{array}{c}\text { 水分利用效率 } \\
\text { WUE }\left(\mathrm{kg} \mathrm{hm}^{-2} \mathrm{~mm}^{-1}\right)\end{array}$ \\
\hline \multirow[t]{3}{*}{2016} & $\mathrm{TT}$ & $22,253.3 \mathrm{~b}$ & $240.1 \mathrm{c}$ & $92.6 \mathrm{~b}$ \\
\hline & VRT & $32,897.3 \mathrm{a}$ & $297.8 \mathrm{~b}$ & $110.6 \mathrm{a}$ \\
\hline & VRT6 & $33,363.0 \mathrm{a}$ & $371.4 \mathrm{a}$ & $36.0 \mathrm{c}$ \\
\hline \multirow[t]{3}{*}{2017} & $\mathrm{TT}$ & $30,388.9 \mathrm{c}$ & $309.0 \mathrm{c}$ & $98.6 \mathrm{~b}$ \\
\hline & VRT & $42,833.3 \mathrm{a}$ & $344.0 \mathrm{~b}$ & $124.9 \mathrm{a}$ \\
\hline & VRT6 & $36,257.7 \mathrm{~b}$ & $410.1 \mathrm{a}$ & $58.1 \mathrm{c}$ \\
\hline
\end{tabular}

在相同年份标记不同小写字母表示处理间在 0.05 水平差异显著。处理同图 3 。

The data in same year with different lowercase letters mean significant difference among treatments at the 0.05 probability level. Treatments are the same as those given in Fig. 3. ET: evapotranspiration; WUE: water use efficiency.

\section{3 讨论}

立式深旋耕作能够显著降低土壤容重 ${ }^{[20-21,23-24]}$ 。 本试验中, VRT6 在 $40 \sim 60 \mathrm{~cm}$ 土层的土壤容重在 2016 年和 2017 年分别较 VRT 显著下降了 $20.0 \%$ 和 $18.1 \%$; 而与 TT 相比, VRT6 在 $0 \sim 60 \mathrm{~cm}$ 土层的土壤 容重显著下降, VRT 在 $0 \sim 40 \mathrm{~cm}$ 土层显著下降。土壤 容重下降将导致土壤饱和含水量、毛管含水量和田 间持水量发生变化 ${ }^{[11-12]}$, 影响土壤水分运移和供应 能力。本试验中, VRT6 在 $0 \sim 10 、 10 \sim 20 、 20 \sim 40$ 和 40 60 $\mathrm{cm}$ 土层的土壤饱和含水量在 2016 年和 2017 年分别较 TT 增加了 $30.8 \% 、 34.8 \% 、 43.7 \% 、 25.5 \%$ 和 $30.7 \%$ 、33.6\%、53.9\%、31.3\%; VRT 则在 $0 \sim 10$ 、 10 20、20 40 cm 土层的饱和含水量在 2016 年和 2017 年分别增加了 $27.0 \% 、 34.1 \% 、 53.4 \%$ 和 $27.3 \%$ 、 $35.1 \%$ 、 $48.0 \%$; VRT6 较 VRT 仅在 $40 \sim 60 \mathrm{~cm}$ 土层显 著增加。毛管含水量和田间持水量呈相似的变化趋 势。由于土壤水分性状发生明显变化, 使 2016 年播 前 VRT6 在 $0 \sim 60 \mathrm{~cm}$ 、VRT 在 $0 \sim 40 \mathrm{~cm}$ 土层的土壤 咜水量分别较 TT 增加了 $12.0 \mathrm{~mm}$ 和 $12.7 \mathrm{~mm}$, 而 VRT6 在 40 60 cm 土层的土壤咜水量较 VRT 增加 了 $2.8 \mathrm{~mm}$ 。虽然 2017 年处理间土壤水分性状的变 化与 2016 年相似, 但土壤䛎水量受马铃薯耗水的 显著影响，与 2016 年呈现不同的变化。因此，增加
旋耕深度能

够显著改变土壤水分性状, 进而影响土壤咜水量和 作物耗水。

调节作物耗水进程是提高旱地作物水分利用 效率和抵御季节性干旱的主要途径之一, 花前水分 的过度消耗会加重季节性干旱胁迫程度 ${ }^{[28]}$, 促进马 铃薯花后耗水能够显著提高产量 ${ }^{[13]}$ 。本试验结果表 明, 在西北黄土高原半干旱旱作区这一降水贵乏地 区, VRT6 的耗水量在播种至现蕾期较 VRT 和 TT 显 著增加, 但干旱年现蕾期 $0 \sim 160 \mathrm{~cm}$ 土层土壤咜水量 在处理间差异不明显, 这主要是土壤的基础咜水量 较高; 由于 2016 年水分的大量消耗, 所以 2017 年 VRT6 的土壤咜水量在现蕾期显著低于 VRT 和 TT。 现蕾期至盛花期是块茎形成的关键时期, 促进该时 期的耗水量对提高马铃薯块茎数量有积极作用 ${ }^{[13]}$ 。 与 $\mathrm{TT}$ 相比, VRT 在干旱年和平水年均能著提高现蕾 期至盛花期的耗水量, 但 VRT6 仅在干旱年提高此 期耗水, 而在 2017 显著低于 $\mathrm{TT}$ 。这主要是 2017 年 VRT6 在现蕾期 $0 \sim 100 \mathrm{~cm}$ 土层的土壤咜水量仅有 $165.8 \mathrm{~mm}$, 而在 2016 年则为 $233.6 \mathrm{~mm}$, 而且此期降 雨量 2016 年为 $34.8 \mathrm{~mm}, 2017$ 年为 $18.7 \mathrm{~mm}$ 。2017 年 VRT6 的土壤咜水量较低, 加之自然降水较少, 导 致耗水明显下降, 对块茎形成产生了不利影响, 并 导致花期土壤咜水显著低于 VRT 和 TT。2016 年花 
后耗水量在 3 个处理间无显著差异, 但 2017 年 VRT6 显著高于 VRT 和 TT, 这主要依赖于此期降水 量高达 $233.5 \mathrm{~mm}$ 。

VRT6 在苗期较高的耗水促进了地上部发育, LAI 在全生育期显著高于 TT, 在现蕾期至收获期显 著高于 VRT, 尤其是在 2017 年块茎膨大期的叶片 SPAD 值显著高于 VRT 和 TT, 这表明 VRT6 促进了 马铃薯在花后的地上部旺长, 这可能导致地上地下 的同化物竞争, 不利于地上同化物向地下运转, 造 成产量明显下降 ${ }^{[29]}$ 。另外, 2016 年在花后的降水量 仅为 $45.8 \mathrm{~mm}$, 而 2017 年则高达 $233.5 \mathrm{~mm}$, 更加剧 了这一不利作用。就全生育期耗水量来看, VRT6 在 2 年均显著高于 VRT 和 TT; 虽然产量高于 TT, 但在 2017 年较 VRT 显著下降, 而且水分利用效率显著低 于 VRT 和 TT, 分别下降了 $53.5 \%$ 和 $41.0 \%$ 。因此, 在 西北黄土高原半干旱雨养区，增加旋耕深度虽然能 够优化土壤的水分特性, 但显著促进了花前的耗水, 这加剧了季节性干旱胁迫对旱作马铃薯产量形成的 不利影响, 导致水分利用效率的显著下降, 而旋耕 深度为 $40 \mathrm{~cm}$ 条件下, 能够在改善土壤水分状况, 优化马铃薯花前花后耗水, 显著提高马铃薯产量和 WUE。然而, 增加旋耕深度能促进马铃薯地上部分 的生长发育, 在水分充足的条件下可能对提高产量 有积极意义, 这需要进一步的研究证实。

\section{4 结论}

在西北黄土高原半干旱雨养区, 旋耕深度增加 至 $60 \mathrm{~cm}$ 时, 显著降低耕作层的土壤容重、提高耕 作层的土壤饱和含水量、毛管含水量和田间持水量, 并提高 2016 年马铃薯播前土壤咜水量; 但促进马铃 薯花前耗水, 降低现蕾期和花期的土壤咜水量, 这 将加剧季节性干旱的胁迫强度, 对马铃薯块茎形成 不利, 导致产量和水分利用效率较 VRT 下降。因此, 在半干旱旱作区，马铃薯种植的立式深旋旋耕深度 以 $40 \mathrm{~cm}$ 为佳, 可优化土壤水分环境和耗水过程, 显著提高产量和水分利用效率。

\section{References}

[1] 朱显谟. 试论黄土高原的生态环境与“土壤水库”一重塑黄土 地的理论依据. 第四纪研究, 2000, 20: 514-520.

Zhu X M. Environment in Loess Plateau and "pedogenic reservoir". Quatern Sci, 2000, 20: 514-520 (in Chinese with English abstract).

[2] 翟振, 李玉义, 逢焕成, 王婧, 张莉, 董国豪, 郭建军, 郭智慧. 黄淮海北部农田犁底层现状及其特征. 中国农业科学, 2016,
49: 2322-2332.

Zhai Z, Li Y Y, Pang H C, Wang J, Zhang L, Dong G H, Guo J J, Guo Z H. Study on present situation and characteristics of plow pan in the northern region of Huang Huai Hai plain. Sci Agric Sin, 2016, 49: 2322-2332 (in Chinese with English abstract).

[3] 王慧杰, 郝建平, 冯瑞云, 南洋, 杨淑巧, 南建福. 微孔深松 耕降低土壤紧实度提高棉花产量与种籽品质. 农业工程学报, 2015, 31(8): 7-14.

Wang H J, Hao J P, Feng R Y, Nan Y, Yang S Q, Nan J F. Microhole subsoiling decreasing soil compaction, and improving yield and seed quality of cotton. Trans CSAE, 2015, 31(8): 7-14 (in Chinese with English abstract).

[4] 姬相云, 王莉萍, 申春晓. 连年旋耕整地对旱地小麦生长发育 及产量影响的调查分析. 种业导刊, 2010, (8): 15-16.

Ji X Y, Wang L P, Shen C X. The investigation and analysis for the effect of continuously rotary tillage on wheat development and yield under rain-fed. J Seed Ind Guide, 2010, (8): 15-16 (in Chinese with English abstract).

[5] 花伟东, 郭亚芬, 张忠学. 坡耕地局部打破犁底层对水分入渗 的影响. 水土保持学报, 2008, 22(5): 213-216.

Hua W D, Guo Y F, Zhang Z X. Influence of plough pan on broke partially slope farmland to moisture content infiltration. $J$ Soil Water Conserv, 2008, 22(5): 213-216 (in Chinese with English abstract).

[6] 谢军红, 张仁陟, 李玲玲, 罗珠珠, 蔡立群, 柴强. 耕作方法 对黄土高原旱作玉米产量和土壤水温特性的影响. 中国生态 农业学报, 2015, 23: 1384-1393.

Xie J H, Zhang R Z, Li L L, Luo Z Z, Cai L Q, Chai Q. Effect of different tillage practice on rain-fed maize yield and soil water/temperature characteristics in the Loess Plateau. Chin $J$ Eco-Agric, 2015, 23: 1384-1393 (in Chinese with English abstract).

[7] Huang G B, Zhang R Z, Li G D, Li L L, Chan K Y, Heenan D P, Chen W, Unkovich M J, Robertson M J, Cullis B R, Bellotti W D. Productivity and sustainability of a spring wheat-field pea rotation in a semiarid environment under conventional and conservation tillage systems. Field Crops Res, 2008, 107: 43-55.

[8] 石磊, 许明祥, 董丽茹, 师晨迪, 邱宇洁. 陕西省农田土壤物 理障碍评价. 干旱地区农业研究, 2016, 34(3): 46-53.

Shi L, Xu M X, Dong L R, Shi C D, Qiu Y J. Evaluation of soil physical obstacles on cropland in Shaanxi Province. Agric Res Arid Areas, 2016, 34(3): 46-53 (in Chinese with English abstract).

[9] 田慎重, 王瑜, 宁堂原, 董晓霞, 董亮, 郑东峰, 郭洪海. 转变 耕作方式对长期旋免耕农田土壤有机碳库的影响. 农业工程 学报, 2016, 32(17): 98-105.

Tian S Z, Wang Y, Ning T Y, Dong X X, Dong L, Zheng D F, Guo $H$ H. Effect of tillage method changes on soil organic carbon pool in farmland under long-term rotary tillage and no tillage. Trans CSAE , 2016, 32(17): 98-105 (in Chinese with English abstract).

[10] 王红光, 于振文, 张永丽, 石玉, 王东. 耕作方式对旱地小麦 耗水特性和干物质积累的影响. 作物学报, 2012, 38: 675-682.

Wang H G, Yu Z W, Zhang Y L, Shi Y, Wang D. Effects of tillage regimes on water consumption and dry matter accumulation in dryland wheat. Acta Agron Sin, 2012, 38: 675-682 (in Chinese with English abstract). 
[11] Tian S Z, Wang Y, Ning T Y, Li N, Zhao H X, Wang B W, Li Z J, Chi S Y. Continued no-till and subsoiling improved soil organic carbon and soil aggregation levels. Agron J, 2014, 106: 212-218.

[12] 刘丹, 张霞, 李军, 王旭东. 渭北旱塬农田不同耕作模式对土 壤性状及玉米产量和水分利用效率的影响. 应用生态学报, 2018, 29: 573-582.

Liu D, Zhang X, Li J, Wang X D. Effects of different tillage patterns on soil properties, maize yield and water use efficiency in Weibei Highland, China. Chin J Appl Ecol, 2018, 29: 573-582 (in Chinese with English abstract).

[13] 侯慧芝, 王娟, 张绪成, 方彦杰, 于显枫, 王红丽, 马一凡. 半 干旱区全膜覆盖垄上微沟种植对土壤水热及马铃薯产量的影 响. 作物学报, 2015, 41: 1582-1590.

Hou H Z, Wang J, Zhang X C, Fang Y J, Yu X F, Wang H L, Ma $Y$ F. Effects of mini-ditch planting with plastic mulching in ridges on soil water content, temperature and potato yield in rain-fed semiarid region. Acta Agron Sin, 2015, 41: 1582-1590 (in Chinese with English abstract).

[14]人民网-甘肃频道. 2017 年马铃薯播种面积达到 1000 万亩. (2018-05-29) [2017-09-28] http://gs.people.com.cn/n2/2017/0 928/c183348-30788332.html.

People. CN-Gansu. The potato cultivation area reaches to 10000 thousands mu in 2017. (2018-05-29) [2017-09-28] http:// gs.people.com.cn/n2/2017/0928/c183348-30788332.html.(in Chinese).

[15] 农业部. 2015 年全国各地蔬菜、西瓜、甜瓜、草莓、马铃薯播 种面积和产量. 中国蔬菜, 2017, 1(1): 18.

Ministry of Agriculture. The nationwide plant area and yield of vegetable, watermelon, melon, strawberry, potato in 2015. China Veget, 2017, 1(1): 18 (in Chinese).

[16] 吕薇, 李军, 岳志芳, 陈宁宁, 王淑兰. 轮耕对渭北旱塬麦田 土壤有机质和全氮含量的影响.中国农业科学, 2015, 48: 3186-3200.

Lyu W, Li J, Yue Z F, Chen N N, Wang S L. Effects of rotational tillage on soil organic matter and soil total nitrogen contents of continuous cropping wheat field in Weibei highland. Sci Agric Sin, 2015, 48: 3186-3200 (in Chinese with English abstract).

[17] 郑成岩, 崔世明, 王东, 于振文, 张永丽, 石玉. 土壤耕作方 式对小麦干物质生产和水分利用效率的影响. 作物学报, 2011, 37: 1432-1440.

Zheng C Y, Cui S M, Wang D, Yu Z W, Zhang Y L, Shi Y. Effects of soil tillage practice on dry matter production and water use efficiency in wheat. Acta Agron Sin, 2011, 37: 1432-1440 (in Chinese with English abstract).

[18] 韦本辉, 甘秀芹, 申章佑, 宁秀呈, 陆柳英, 韦广泼, 李艳英, 胡泊, 刘斌, 吴延勇. 粉垄栽培甘蔗试验增产效果. 中国农业 科学, 2011, 44: 4544-4550.

Wei B H, Gan X Q, Shen Z Y, Ning X C, Lu L Y, Wei G B, Li Y Y, $\mathrm{Hu}$ B, Liu B, Wu Y Y. Yield increase of smash-ridging cultivation of sugarcane. Sci Agric Sin, 2011, 44: 4544-4550 (in Chinese with English abstract).

[19] 韦本辉, 甘秀芹, 申章佑, 宁秀呈, 韦广泼, 陆柳英, 胡泊, 刘 斌, 李艳英, 吴延勇. 粉垄栽培木薯增产效果及理论探讨. 中 国农学通报, 2011, 27(21): 78-81.
Wei B H, Gan X Q, Shen Z Y, Ning X C, Wei G P, Lu L Y, Hu B, Liu B, Li Y Y, Wu Y Y. Production increasing and discussion in theory of smash-ridging cultivate cassava. Chin Agric Sci Bull, 2011, 27(21): 78-81 (in Chinese with English abstract).

[20] 李华, 逢焕成, 任天志, 李轶冰, 汪仁, 牛世伟, 安景文. 深旋 松耕作法对东北棕壤物理性状及春玉米生长的影响. 中国农 业科学, 2013, 46: 647-656.

Li H, Pang H C, Ren T Z, Li Y B, Wang R, Niu S W, An J W. Effects of deep rotary-subsoiling tillage method on brown physical properties and maize growth in northeast of China. Sci Agric Sin , 2013, 46: 647-656 (in Chinese with English abstract).

[21] Zhai L C, Xu P, Zhang Z B, Li S K, Xie R Z, Zhai L F, Wei B H. Effects of deep vertical rotary tillage on dry matter accumulation and grain yield of summer maize in the Huang-Huai-Hai plain of China. Soil Tillage Res, 2017, 170: 167-174.

[22] 李轶冰, 逢焕成, 杨雪, 李玉义, 李华, 任天志, 董国豪, 郭良 海. 粉垄耕作对黄淮海北部土壤水分及其利用效率的影响. 生态学报, 2013, 33: 7478-7486.

Li Y B, Pang H C, Yang X, Li Y Y, Li H, Ren T Z, Dong G H, Guo L H. Effects of deep vertically rotary tillage on soil water and water use efficiency in northern China's Huang-Huai-Hai Region. Acta Ecol Sin, 2013, 33: 7478-7486 (in Chinese with English abstract).

[23] 张绪成, 马一凡, 于显枫, 侯慧芝, 王红丽, 方彦杰. 西北半 干旱区深旋松耕作对马铃薯水分利用和产量的影响. 应用生 态学报, 2018, 29: 3293-3301.

Zhang X C, Ma Y F, Yu X F, Hou H Z, Wang H L, Fang Y J. Effects of vertically rotary sub-soiling tillage on water utilization and yield of potato in semiarid area of northwest China. Chin J Appl Ecol, 2018, 29: 3293-3301 (in Chinese with English abstract).

[24] Zhang X C, Ma Y F, Yu X F, Hou H Z, Wang H L, Fang Y J. Effects of vertical rotary subsoiling with plastic mulching on soil water availability and potato yield on a semiarid Loess plateau, China. Soil Tillage Res, 2020, 199: 104591.

[25] 冯晔, 张玉霞, 王春雷, 张建华, 包额尔敦嘎, 郑威, 纪晓波. 不同深松深度对玉米根系活性及产量的影响. 内蒙古民族大 学学报(自然科学版), 2013, 28(2): 196-199.

Feng Y, Zhang Y X, Wang C L, Zhang J H, Bao E R D G, Zheng W, Ji X B. A influence of different subsoiling depth on corn root activity and output. J Inner Mongo Univ (Nat Sci Edn), 2013, 28(2): 196-199 (in Chinese with English abstract).

[26] 高建胜, 董国豪, 郭建军, 郭良海, 郭智慧, 崔慧妮. 耕层厚 度对冬小麦农艺性状及产量的影响. 山东农业科学, 2018, 50(8): 54-57.

Gao J S, Dong G H, Guo J J, Guo L H, Guo Z H, Cui H N. Effects of topsoil thickness on agronomic trait and yield of winter wheat. Shandong Agric Sci, 2018, 50(8): 54-57 (in Chinese with English abstract).

[27] 张莉, 翟振, 逢博, 李玉义, 王婧, 逢焕成, 韦本辉, 王庆伟, 綦少伟. 深旋松耕改善耕层结构促进马铃薯增产. 中国土壤 与肥料, 2017, (4): 17-23.

Zhang L, Zhai Z, Pang B, Li Y Y, Wang J, Pang H C, Wei B H, Wang Q W, Qi S W. Deep vertically rotary tillage improves soil structure and tuber yield of potato. Soil Fert Sci China, 2017, (4): 17-23 (in Chinese with English abstract). 
[28] 张福锁, 范明生. 主要粮食作物高产栽培与资源高效利用的 基础研究. 北京: 中国农业出版社, 2013. pp 572-578.

Zhang F S, Fan M S. The Theoretic Research on High Yield and Resource Utilization Cultivation of Main Food Crops. Beijing: China Agriculture Press, 2013. pp 572-578 (in Chinese).

[29] 张春娟, 冯乃杰, 李建英, 郑殿峰. 植物生长物质对马铃薯
叶片同化物及产量品质的影响. 中国马铃薯, 2009, 23: 325-328.

Zhang C J, Feng N J, Li J Y, Zheng D F. Effects of plant growth substances on the metabolism assimilation of leaves, yield and quality in potato. Chin Potato J, 2009, 23: 325-328 (in Chinese with English abstract). 